\title{
Gold Nanoparticle-Mediated Depolarization of Membrane Potential is Dependent on Concentration and Tethering Distance from the Plasma Membrane
}

\author{
Megan E. Muroski†, Eunkeu Oh`, Okhil K. Nag†, Igor L. Medintz ${ }^{\dagger}$, Alexander L. Efros ${ }^{\ddagger}$, \\ Alan Huston", and James B. Delehanty ${ }^{\dagger *}$
}

$\dagger$ Center for Bio/Molecular Science and Engineering, Code 6900, "Optical Sciences Division, Code 5600, and $¥$ Materials Science and Technology Division, Code 6300, U.S. Naval Research Laboratory, Washington, DC 20375 
Table of Contents

Supporting Information Figures

a) Figure S1. Comparison of cellular internalization rate of AuNP-PEG $1000-$ Chol NPs versus AuNPs conjugated to polyarginine-containing peptides. 


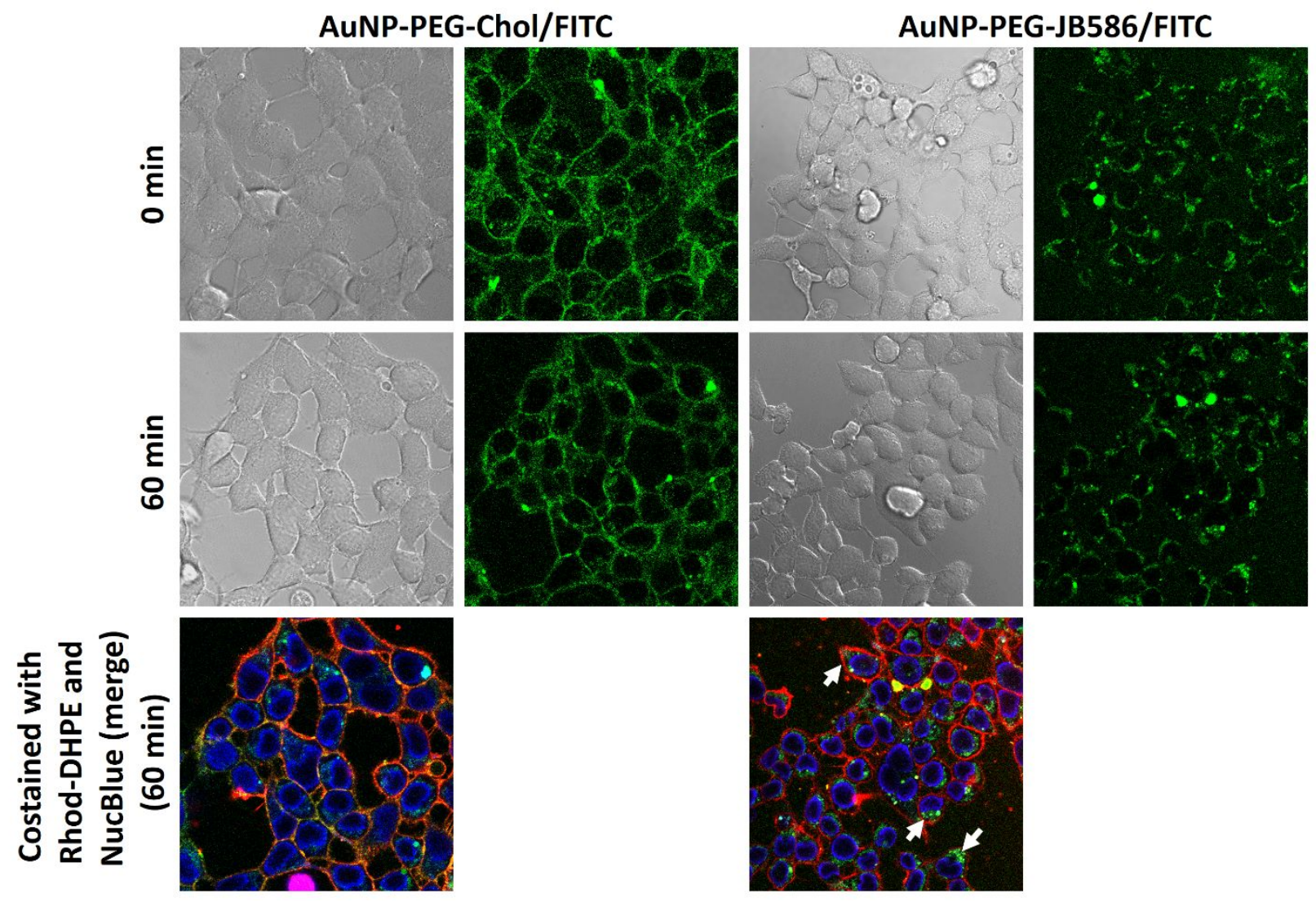

Figure S1. Comparison of the internalization rate of AuNP-PEG-Chol conjugates versus AuNPs conjugated to polyarginine-containing peptides. The peptide used (JB586 (sequence WGRRVRRRIRRP ${ }_{9}$ GGK) has a unique C-terminal lysine for EDC conjugation to AuNPs similar to the procedure in the Methods in the main manuscript). Arginine $(\mathrm{R})$ residues promote plasma membrane interaction are underlined. HEK $293 \mathrm{~T} / 17$ cells were seeded to $35 \mathrm{~mm}$ dishes $\left(7 \times 10^{4}\right.$ cells $/ \mathrm{mL}$ ). After $24 \mathrm{~h}$ the cells were incubated with $5 \mathrm{nM}$ of AuNP-PEG ${ }_{1000}-\mathrm{Chol} / \mathrm{FITC}$ or AuNPPEG-JB586/FITC in DPBS at $37^{\circ} \mathrm{C}$ for $20 \mathrm{~min}$. The solutions were removed, the cell monolayers were washed with DPBS, and the cells were incubated in LCIS for $1 \mathrm{~h}$ at $37^{\circ} \mathrm{C}$. At the end of this incubation period, the cells were labeled with the membrane dye Lissamine ${ }^{\mathrm{TM}}$ Rhodamine B 1,2Dihexadecanoyl-sn-Glycero-3-Phosphoethanolamine (Rhod-DHPE, ThermoFisher) and NucBlue ${ }^{\circledR}$ Live Reagent (nuclear staining dye, ThermoFisher). The cells were imaged by CLSM and the degree of colocalization of the AuNP signal with the Rhod-DHPE marker was quantified using Pearson's colocalization coefficient. The AuNP-PEG-Chol/FITC signal showed $\sim 85 \%$ colocalization with the membrane marker while AuNPs decorated with the JB586 peptide (which bears a poly-arginine domain and has been shown to mediate rapid endocytosis of NPs) ${ }^{1}$ showed $\sim 32 \%$ colocalization with the membrane marker. Note the large degree of internalized AuNPs for the JB586 peptide (white arrows in the merged panel, bottom right). Scale bar is $20 \mu \mathrm{m}$. 